\title{
Airborne Platanus Pollen Analysis by EPMA
}

\author{
L. Duque*, F. Guimarães**, H. Ribeiro*, R. Sousa* and I. Abreu***** \\ * Grupo Ambiente e Sociedade, Centro de Geologia da Universidade do Porto, Portugal \\ ** Laboratório Nacional de Energia e Geologia, S. Mamede Infesta, Portugal \\ *** Departamento de Biologia da Faculdade de Ciências da Universidade do Porto, Portugal
}

Particles of anthropogenic and biological origin, minerals and gaseous elements are the major constituents of the aerosol. Pollen is a biological component of the aerosol, found in suspension with other pollutants. In recent years, research has been conducted on the crossed effects between non-biological and biological pollutants on allergy worsening in susceptible individuals or on the development of symptoms in nonsymptomatic ones. Platanus spp pollen is abundantly present in the atmosphere of Porto in early spring and is known to promote allergic respiratory symptoms. The aim of this study was to characterize possible alterations of the main elements present on the Platanus spp. pollen wall under different atmospheric conditions in the coastal city of Porto, Portugal, using EPMA.

In the current work, we compared airborne and control Platanus spp. pollen. Airborne pollen sampling was performed using a 7-day Hirst-type volumetric spore trap (Burkard Co. Limited) set on the roof of the Faculty of Sciences in Porto. In this device, the airborne particles impact on a double-sided adhesive carbon tape supported on a clockwork-driven drum, which rotates once a week. After exposure, the tape was cut into daily segments and mounted on slides. For this study, four days with different meteorological conditions were taken into account. Control pollen was collected directly from Platanus spp. trees in public gardens and sidewalks, dried at $27^{\circ} \mathrm{C}$ and sieved. To maintain similar conditions of analysis, this sample was also mounted over adhesive carbon tape. All samples were carbon coated. Qualitative and quantitative analyses were performed with a Field Emission Electron Probe Microanalyser (EPMA) JEOL JXA-8500F. Since analysed pollen size is about $20 \mu \mathrm{m}$, EDS qualitative analyses were conducted at 10 $\mathrm{kV}, 10 \mathrm{nA}$, during $15 \mathrm{~s}$ and WDS quantitative analyses were performed at $6 \mathrm{kV}, 15 \mathrm{nA}$. These accelerating voltages ensure that the volume of excitation caused by the beam is smaller than pollen size. In this work, we tried to avoid the irradiation of external particles adhered to the pollen wall in order to focus on the pollen itself.

Airborne Platanus spp. pollen often showed mineral particles adhered to its wall and its microreticulate exine was sometimes partially or completely filled with extraneous material (Figure 1). EDS qualitative analysis to airborne and control samples allowed us to choose $\mathrm{N}, \mathrm{Cl}, \mathrm{Ca}, \mathrm{Na}, \mathrm{S}, \mathrm{O}, \mathrm{P}, \mathrm{Mg}, \mathrm{K}$ and $\mathrm{Si}$ to the subsequent analyses. WDS quantitative analyses showed that airborne pollen had a higher content of the majority of the elements analysed than control pollen (Figure 2). The extent of this augmentation varied with atmospheric conditions. The highest increase in $\mathrm{Mg}, \mathrm{Cl}$, and $\mathrm{S}$ occurred when the relative humidity was maximal and the prevailing winds came from NNW and $\mathrm{E}$. The $\mathrm{Na}$ mass percent was the highest when the winds came predominantly from $\mathrm{SW}$ and relative humidity was high. $\mathrm{Mg}^{2+}, \mathrm{Cl}^{-}, \mathrm{Na}^{+}$and $\mathrm{SO}_{4}{ }^{2-}$ are the main ions that constitute sea water salinity and the deposition of these elements on the pollen wall was more evident when the relative humidity was elevated and the wind blew, at least partially, from the shore (W). On the first sampling date, when the wind came mostly from the sea, was also when the Si content increase was the highest, possibly because of the sandy beaches existing in that direction. Increases in $\mathrm{N}, \mathrm{P}$ and $\mathrm{K}$ were not significantly different between the four days, suggesting that meteorological conditions do not affect the deposition of these elements on the pollen wall. Ca is the only element whose percentage was lower in airborne than in control pollen, indicating that, at least in the studied days, flying did not add calcium to the pollen wall. 
Our results showed that airborne Platanus spp. pollen acquires an external coating, becomes heavier and changes significantly its composition. Moreover, it was observed some influence of relative humidity and direction of prevailing winds on the coating properties. It is suggested that pollutants, by attaching to the pollen wall, may assist the release of inhaled pollen allergens or/and promote the access of allergens to the immune system cells. We are currently studying if the modifications that occurred interfere with the allergenic potential of the pollen.
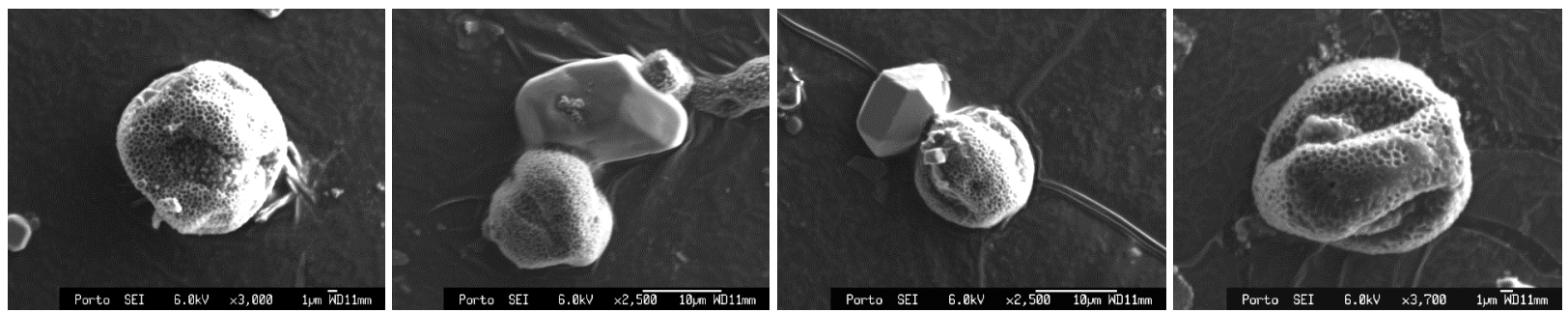

Figure 1. Airborne Platanus spp. pollen grains with adhered particles. The far right image shows a pollen grain with the ornamentation partially filled with extraneous materials.

Element mass \%

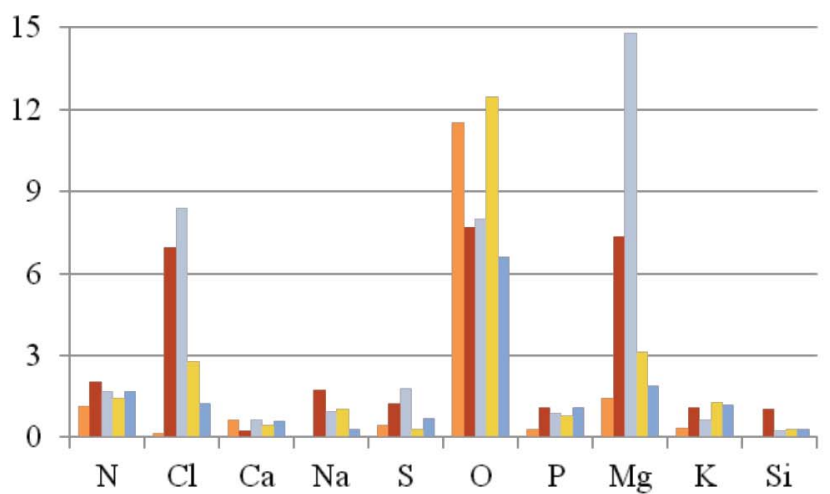

\begin{tabular}{lccccc}
\hline & T & RH & WS & WD & Pr \\
\hline$\square$ Control $(\mathrm{n}=14)$ & - & - & - & - & - \\
$\square 74(\mathrm{n}=15)$ & 12.0 & 72.9 & 3.23 & SW & 0.14 \\
$\square 7(\mathrm{n}=16)$ & 10.6 & 85.3 & 1.87 & NNW-E & 0.01 \\
$\square 8(\mathrm{n}=15)$ & 15.2 & 59.6 & 2.21 & $\mathrm{NE}$ & 0.00 \\
$\square 8(\mathrm{n}=19)$ & 18.6 & 37.2 & 3.18 & $\mathrm{NE}$ & 0.00 \\
\hline
\end{tabular}

Figure 2 - Mass \% of analysed elements of control and airborne Platanus spp. pollen samples and meteorological conditions on the sampling dates. Sample numbers correspond to the Julian day. T Temperature $\left({ }^{\circ} \mathrm{C}\right)$; RH - Relative Humidity (\%); WS - Wind speed (m/s); WD - Prevailing wind direction; $\mathrm{Pr}$ - Precipitation ( $\mathrm{mm}$ ).

This work was supported by FEDER funds through the Operational Program Competitiveness Factors COMPETE and National Funds through FCT - Foundation for Science and Technology in the project Ref PTDC/AAC-AMB/102796/2008 and POCI 2010. Third author benefits from a scholarship (SFRH/BDP/43604/2008) financed by QREN-POPH and FCT. 